\title{
Clinicopathological Characteristics and Prognostic Factors of Patients with Gastric Cancer Accompanying Neuroendocrine Differentiation (NEDGC)
}

This article was published in the following Dove Press journal:

Cancer Management and Research

\author{
Ya-Ping Wang (D) \\ Jun Hong \\ Jian Wang \\ Yi-Bing Bei \\ Han-Kun Hao \\ Lu-Chun Hua
}

Department of Surgery, Huashan Hospital, Fudan University, Shanghai 200040, People's Republic of China
Correspondence: Lu-Chun Hua Email1339105I806@I89.cn

\begin{abstract}
Aim: Gastric carcinoma with neuroendocrine differentiation (NEDGC) is a relatively rare pathologic diagnosis in clinical practice, which has no specific guidelines or treatment recommendations yet. In this study, we aim to investigate the clinicopathological characteristics and prognostic factors of this disease.

Patients and Methods: We retrospectively analyzed clinicopathological data from a series of 82 NEDGC patients who underwent surgery for gastrectomy at Huashan Hospital Fudan University between January 2007 and December 2018. Furthermore, a series of 50 cases were used to analyze 3-year overall survival (OS).

Results: Ages of the patients ranged from 26 to 83 years (M:F, 4.8:1). The majority of patients suffered from some symptoms $(97.6 \%)$, as the most common one was abdominal pain $(48.8 \%)$. Most of the tumors were $\geq 5 \mathrm{~cm}(53.7 \%)$, in the lower part of the stomach (47.5\%), and with advanced $\mathrm{T}(87.8 \% \geq \mathrm{T} 3)$ and $\mathrm{N}(67.1 \% \geq \mathrm{N} 1)$ stage. As to the neuroendocrine markers, Syn showed a slight advantage on sensitivity than $\mathrm{CgA}$ (79.3 and 75.6\%, respectively). The 3-year OS was 54\%. Advanced T stage ( $\geq \mathrm{T} 3$ ) of the primary tumor, positive lymphovascular invasion (LVI), large tumor size $(5.5 \mathrm{~cm})$, high neutrophil-to-lymphocyte ratio (NLR, 2.51), and low prealbumin level $(173.87 \mathrm{mg} / \mathrm{L})$ were associated with inferior OS based on the univariate analysis. Low preoperative hemoglobin level $(113.87 \mathrm{~g} / \mathrm{L})$, laparoscopic-assisted gastrectomy, and advanced N stage (N3) were three independent risk factors for 3-year OS of NEDGC patients in both univariate and multivariate analysis.

Conclusion: The TN staging system for gastric adenocarcinoma also has a prognostic value for NEDGC patients, while N3 stage works as an independent predictor of patients' survival. Since most of the NEDGC patients were in advanced stage, proper indications to perform operative laparoscopy should be selected.
\end{abstract}

Keywords: gastric cancer, neuroendocrine cell differentiation, prognosis, surgical treatment

\section{Introduction}

Gastric carcinoma with neuroendocrine differentiation (NEDGC) is a relatively rare pathologic diagnosis in clinical practice. According to the definition by the World Health Organization (WHO) in 2010, ${ }^{1}$ NEDGC is a gastric neoplasm in which differentiated neuroendocrine (NE) cells are scattered as single cells or cell clusters among gastric carcinoma cells. NEDGC distinguishes itself from mixed adeno-neuroendocrine carcinoma (MANEC), which has been renamed to mixed neuroendocrine-non- 
neuroendocrine neoplasms (MiNENs) in the WHO 2017 classification, ${ }^{2,3}$ by the volume of epithelial and NE cells components within the same tumor tissue.

However, since only ten years passed from the establishment and standardization of the NEDGC diagnostic system, little information of this disease is available. A few studies have shown the gradually increasing frequency recently, and in particular, revealed worse prognosis of NEDGC than those gastric cancer without NED. ${ }^{4-7}$ Therefore, is it inappropriate to classify and treat NEDGC just according to adenocarcinoma? Are specific guidelines or treatment recommendations essential for this tumor type?

In this study, we retrospectively studied 82 cases of NEDGC, which is a relatively large volume to our best knowledge, aimed to investigate the clinicopathological characteristics of NEDGC. Furthermore, in a series of 50 cases including, we analyzed prognostic factors of NEDGC after radical gastrectomy.

\section{Patients and Methods}

\section{Patient Selection}

We retrospectively analyzed clinicopathological data from patients diagnosed as NEDGC at Huashan Hospital Fudan University between January 2007 and December 2018. All the patients enrolled diagnosed pathologically after $\mathrm{R} 0$ resection with D2 lymphadenectomy and without the absence of clinicopathological data. The exclusion criteria included preoperative findings of distant metastasis or other original tumor, and adjuvant chemotherapy or radiotherapy. As to the prognosis-related analysis, two more criteria as followed included: (1) those with 3-year OS; (2) those with complete follow-up clinical data. The detailed flowchart of the cohort is shown in Figure 1. This study was approved by Institutional Review Board of Huashan Hospital (HIRB; Shanghai, China) (No. KY2019-482). Written informed consent was obtained from all participants which included their clinicopathological data and survival outcomes. We confirmed that this report was conducted in accordance with the Declaration of Helsinki.

\section{Diagnosis of NEDGC}

The NEDGC diagnosis was confirmed by the general hematoxylin and eosin (H\&E) histology, as well as by immunohistochemistry (IHC). More specifically, slices of each case were reviewed for both histological features of neuroendocrine neoplasms and IHC positivity for neuroendocrine markers, including synaptophysin (Syn) and chromogranin A (CgA). With the WHO 2010 classification $^{1}$ and expert consensus on gastrointestinal neuroendocrine oncology in China, ${ }^{8}$ NED was defined as the immunopositivity of one of the two neuroendocrine markers (Syn and $\mathrm{CgA}$ ), and less than $30 \%$ volume within the area of the gastric adenocarcinoma. Ki67 index was evaluated in all cases for counting nuclear proliferation.

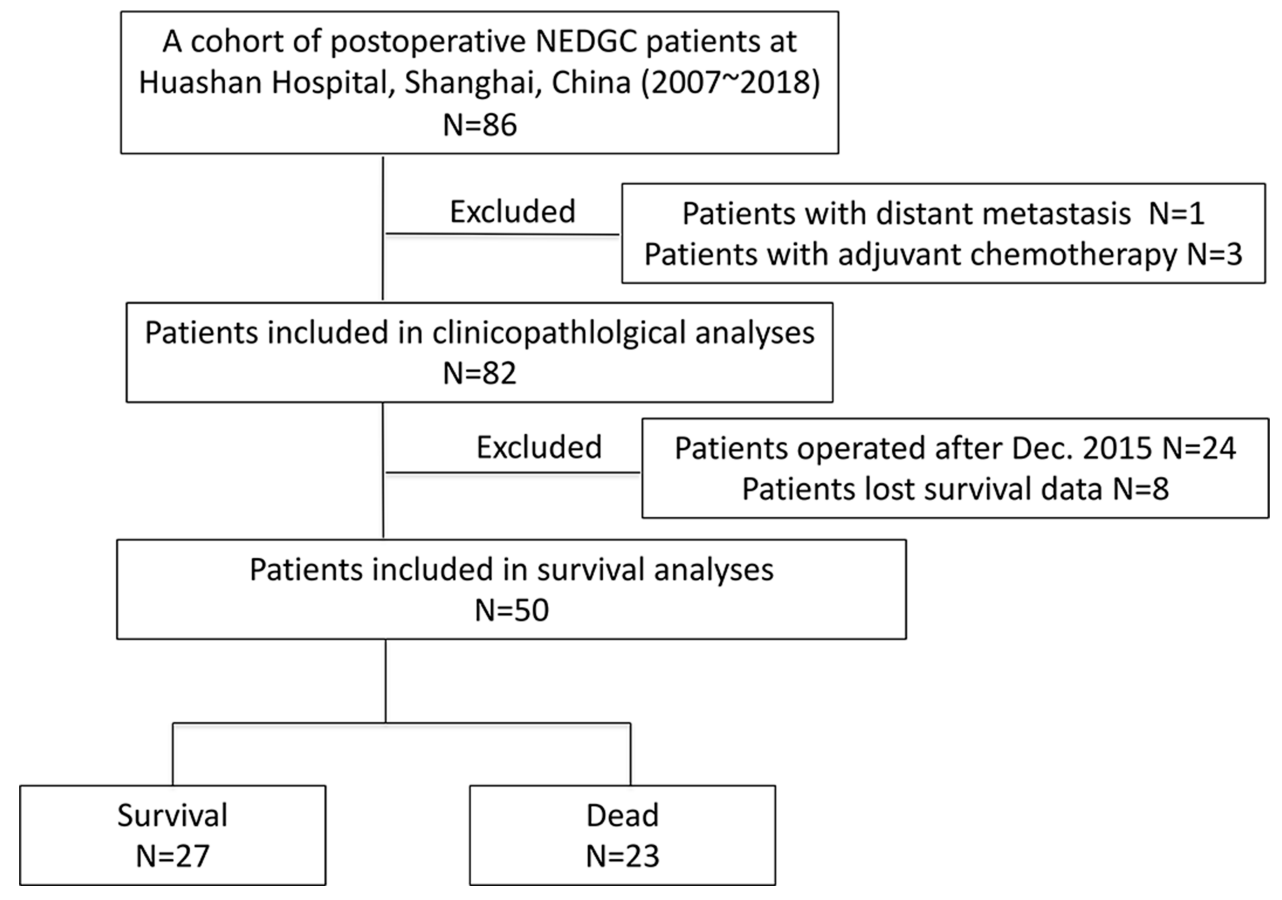

Figure I Flowchart of patients enrolled. 


\section{Treatment}

The surgical method, including radical total gastrectomy and radical distal gastrectomy, was selected depending on the tumor location. Adjuvant chemotherapy based on 5-FU plus platinum-based drugs was taken for the patients with stage II or more advanced stage postoperatively.

Surgical resection margins R0 was defined as complete resection of the localized tumor, which was both confirmed during the operation by the surgeon and under macroscopic by the pathologists.

\section{Clinicopathological Characteristics}

Clinical data such as age, gender, body mass index (BMI), tumor location, tumor size, symptoms, complications, surgical treatment, operation time, preoperative blood biochemistry data, and follow-up information were recorded. Pathological data such as tumor TN stage, lymphovascular invasion (LVI), perineural invasion (PNI), expression of Syn and $\mathrm{CgA}$, and $\mathrm{Ki}-67$ index were also recorded.

Staging of the tumor was defined according to the American Joint Committee on Cancer (AJCC) Cancer Staging Manual for carcinoma of the stomach (8th Edn.). ${ }^{9}$ Tumor size was evaluated according to the maximum tumor dimension.

\section{Survival Status}

In the present study, we used 3-year OS as the primary outcome. OS was defined as the interval between date of surgery and date of last follow-up or death.

Patients were followed up every 3 months during the first 2 years and then every 6 months from 2 to 5 years, and then annually. Follow-up data were obtained by phone, outpatient visits, and our clinical database, and the date of the last follow-up was December 2019.

\section{Statistical Analyses}

Categorical and continuous clinicopathological characteristics of the cohort were firstly described using frequency (percentage) and median (range), respectively. We performed Log-rank tests to compare the 3-year OS rates across the $\mathrm{T}$ stages and $\mathrm{N}$ stages. The relationships between all variables and outcomes were quantified by univariate Cox regression analysis. Prognostic variables with $P<0.05$ from univariate analyses were further included in a multivariate Cox proportional hazards analysis. The Statistical Package R, version 0.4.3 (R Foundation for Statistical Computing, Vienna,
Austria) was used for statistical analysis. $P<0.05$ was considered statistically significant.

\section{Results}

\section{Clinicopathological Characteristics}

A total of 82 eligible patients with NEDGC diagnosed between 2007 and 2018 were included in the study. The clinicopathological characteristics of these patients are shown in Table 1. The median age was 62 years (range: $26 \sim 83$ years), and $82.9 \%$ of the patients were male. The majority of patients suffered from some symptoms (97.6\%), as the most common one was abdominal pain (48.8\%). Other symptoms were abdominal distension (43.9\%), acid reflux (24.4\%), alimentary tract hemorrhage (24.4\%), anemia (12.2\%) and dysphagia (12.2\%). No carcinoid syndrome was found in these cases. As to the other systemic disease complicated, hypertension is the most common one (26.8\%), followed by chronic gastritis $(11 \%)$ and diabetes $(9.8 \%)$.

Tumor sizes ranged from 0.6 to $12 \mathrm{~cm}$, with a median size was $5 \mathrm{~cm}$. Most of the tumors were $\geq 5 \mathrm{~cm}$ ( 44 cases, $53.7 \%$ ). In terms of location, $29.3 \%$ of tumors were located in the upper, $23.2 \%$ in the middle, and $47.5 \%$ in the lower part of the stomach. According to AJCC 8th edition for gastric cancer, 12 patients were in stage I, 18 were in stage II, and 52 were in stage III. Although the majority of the patients were in advanced $\mathrm{T}$ stage $(87.8 \% \mathrm{~T} 3$ or $\mathrm{T} 4 \mathrm{a})$ and had lymph nodes metastasis $(67.1 \%)$, most of them without LVI and PNI (72\% and $90.2 \%$, respectively). As to the neuroendocrine markers, Syn showed a slight advantage on sensitivity than $\mathrm{CgA}(79.3 \%$ and $75.6 \%$, respectively). High Ki-67 positive index also demonstrated in our study as 68 cases $(82.9 \%) \geq 30 \%, 35$ cases $(42.7 \%) \geq 60 \%$ including (Table 1 ).

\section{Survival}

As shown in Figure 1, 3-year OS was 54\%, with the median survival time was 41 months. According to the univariate analysis, operation under laparoscopy, advanced $\mathrm{T}(\geq \mathrm{T} 3)$ or $\mathrm{N}$ (N3) stage of the primary tumor, positive LVI, large tumor size $(5.5 \mathrm{~cm})$, high neutrophil-to-lymphocyte ratio (NLR, 2.51), low hemoglobin and prealbumin level $(113.87 \mathrm{~g} / \mathrm{L}$ and $173.87 \mathrm{mg} / \mathrm{L}$, respectively) were associated with poor OS $(P<0.05$; Tables 2 and 3; Figures 2-4). Among them, low preoperative hemoglobin level (HR 0.979; 95\% CI: $0.958-$ $1.000 ; P=0.046$ ), laparoscopic-assisted gastrectomy (HR 3.058; 95\% CI: $1.169-8.000 ; P=0.023$ ), and N3 stage (HR 11.977; 95\% CI: $3.025-47.420 ; P<0.001)$ were three independent risk factors for OS in the multivariate analysis (Table 4). 
Table I Clinicopathological Characteristics of NEDGC Patients

\begin{tabular}{|c|c|c|}
\hline \multirow{2}{*}{$\begin{array}{l}\text { Category } \\
\text { Median age (range) }\end{array}$} & \multicolumn{2}{|c|}{ Value } \\
\hline & 62 & $(26-83)$ \\
\hline \multicolumn{3}{|l|}{ Gender } \\
\hline Male & 68 & $(82.9 \%)$ \\
\hline Female & 14 & $(17.1 \%)$ \\
\hline \multicolumn{3}{|l|}{ BMI $\left(\mathrm{kg} / \mathrm{m}^{2}\right)$} \\
\hline$<18.5$ & 5 & $(6.1 \%)$ \\
\hline $18.5-23.99$ & 51 & $(62.2 \%)$ \\
\hline$\geq 24$ & 26 & $(31.7 \%)$ \\
\hline \multicolumn{3}{|l|}{ Comorbidities } \\
\hline \multicolumn{3}{|l|}{ Hypertension } \\
\hline Yes & 22 & $(26.8 \%)$ \\
\hline No & 60 & $(73.2 \%)$ \\
\hline \multicolumn{3}{|l|}{ Diabetes } \\
\hline Yes & 8 & $(9.8 \%)$ \\
\hline No & 74 & $(90.2 \%)$ \\
\hline \multicolumn{3}{|l|}{ Chronic gastritis } \\
\hline Yes & 9 & $(11.0 \%)$ \\
\hline No & 73 & $(89.0 \%)$ \\
\hline \multicolumn{3}{|l|}{ Cardiac disease } \\
\hline Yes & I & $(1.2 \%)$ \\
\hline No & 81 & $(98.8 \%)$ \\
\hline \multicolumn{3}{|l|}{ Chronic gastritis history } \\
\hline Yes & 9 & $(11.0 \%)$ \\
\hline No & 73 & $(89.0 \%)$ \\
\hline \multicolumn{3}{|l|}{ Family history } \\
\hline Yes & I & $(1.2 \%)$ \\
\hline No & 81 & $(98.8 \%)$ \\
\hline \multicolumn{3}{|l|}{ Drinking history } \\
\hline Yes & 12 & $(14.6 \%)$ \\
\hline No & 70 & $(85.4 \%)$ \\
\hline \multicolumn{3}{|l|}{ Smoking history } \\
\hline Yes & 18 & $(22.0 \%)$ \\
\hline No & 64 & $(78.0 \%)$ \\
\hline Presenting symptoms & 80 & $(97.6 \%)$ \\
\hline \multicolumn{3}{|l|}{ Weight loss } \\
\hline Yes & 23 & $(28.0 \%)$ \\
\hline No & 59 & $(72.0 \%)$ \\
\hline \multicolumn{3}{|l|}{ Abdominal pain } \\
\hline Yes & 40 & $(48.8 \%)$ \\
\hline No & 42 & $(51.2 \%)$ \\
\hline \multicolumn{3}{|l|}{ Abdominal distension } \\
\hline Yes & 36 & $(43.9 \%)$ \\
\hline No & 46 & $(56.1 \%)$ \\
\hline Dysphagia & & \\
\hline
\end{tabular}

(Continued)
Table I (Continued).

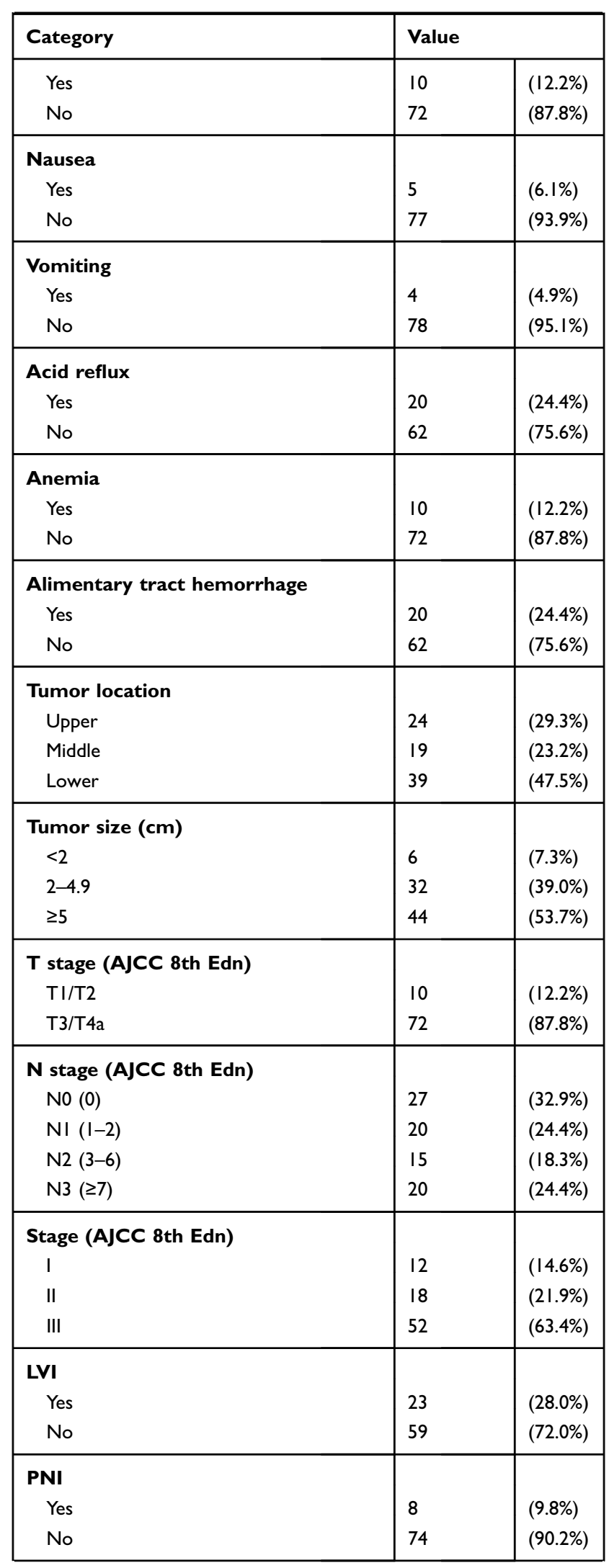

(Continued) 
Table I (Continued).

\begin{tabular}{|c|l|l|}
\hline Category & \multicolumn{2}{|l|}{ Value } \\
\hline CgA & & \\
+ & 62 & $(75.6 \%)$ \\
- & 20 & $(24.4 \%)$ \\
\hline Syn & & \\
+ & 65 & $(79.3 \%)$ \\
- & 17 & $(20.7 \%)$ \\
\hline Ki-67 positive index (\%) & & \\
$<30$ & 14 & $(17.1 \%)$ \\
$30-59.9$ & 33 & $(40.2 \%)$ \\
$\geq 60$ & 35 & $(42.7 \%)$ \\
\hline
\end{tabular}

Abbreviations: LVI, lymphovascular invasion; $\mathrm{PNI}$, perineural invasion; $\mathrm{CgA}$, chromogranin A; Syn, synaptophysin.

\section{Discussion}

Gastric cancer is one of the most common malignancies worldwide, especially in the EAST. In recent years, a lot of progress has been made in surgery and adjuvant treatment, but the high mortality rate of this disease is still an unsolved problem, which attributed to detection too late. $^{10}$ In this retrospective study, we regret to find that only $14.6 \%$ of cases were in stage I, and only one person diagnosed by physical examination with fibro gastro endoscope, who had no symptoms before. Since symptoms tend to show up in the course of diseases progressing, greater awareness should be raised to popularize routine physical examination, including endoscope. On the other hand, since the high level of morbidity and mortality of gastric cancer (with or without NED) in our country, it is a challenge to improve the techniques in tumor screening and treatment in this field.

As described previously, both $\mathrm{CgA}$ and Syn should be detected as diagnostic criteria of neuroendocrine. IHC markers $\mathrm{CgA}$ was reported as a nuclear protein with high specificity, while Syn was a transmembrane protein with high sensitivity. ${ }^{11}$ Consistent with these studies is our finding. It reflects the importance of combined detection of these two markers in improving the sensitivity and specificity of NEDGC's diagnosis. However, although ki-67 is the most important prognostic and predictive biomarker in patients with $\mathrm{g}-\mathrm{NEN},{ }^{12,13}$ its expression level in patients with NEDGC has no significant correlation with survival, which verified the rationality that classifies NEDGC as gastric adenocarcinoma than as g-NEN.
Table 2 Univariable (Categorical Variables) Cox Regression Analyses of OS

\begin{tabular}{|c|c|c|c|c|c|}
\hline Category & $\mathbf{n}$ & $\begin{array}{l}\text { 3-y OS } \\
(\%)\end{array}$ & HR & $95 \% \mathrm{Cl}$ & $\mathbf{P}$ \\
\hline \multicolumn{6}{|l|}{ Gender } \\
\hline Male & 39 & 53.85 & 0.95 & $0.35-2.55$ & 0.913 \\
\hline Female & 11 & 54.55 & & & \\
\hline \multicolumn{6}{|l|}{$\begin{array}{l}\text { Hypertension } \\
\text { complicated }\end{array}$} \\
\hline Yes & 13 & 38.46 & 0.60 & $0.25-1.41$ & 0.243 \\
\hline No & 37 & 59.46 & & & \\
\hline \multicolumn{6}{|l|}{$\begin{array}{l}\text { Diabetes } \\
\text { complicated }\end{array}$} \\
\hline Yes & 7 & 28.57 & 0.38 & $0.14-1.03$ & 0.057 \\
\hline No & 43 & 58.14 & & & \\
\hline \multicolumn{6}{|l|}{$\begin{array}{l}\text { Chronic gastritis } \\
\text { history }\end{array}$} \\
\hline Yes & 7 & 71.43 & 2.44 & $0.57-10.00$ & 0.230 \\
\hline No & 43 & 51.16 & & & \\
\hline \multicolumn{6}{|l|}{ Smoking history } \\
\hline Yes & 9 & 66.67 & 1.59 & $0.47-5.26$ & 0.448 \\
\hline No & 41 & 51.22 & & & \\
\hline \multicolumn{6}{|l|}{ Drinking history } \\
\hline Yes & 7 & 57.14 & 1.12 & $0.33-3.70$ & 0.856 \\
\hline No & 43 & 53.49 & & & \\
\hline \multicolumn{6}{|l|}{ Surgical method } \\
\hline Laparotomy & 39 & 64.10 & 3.49 & I.47-8.27 & 0.004 \\
\hline Laparoscopic & 11 & 18.18 & & & \\
\hline \multicolumn{6}{|l|}{ Operation types } \\
\hline $\begin{array}{l}\text { Total } \\
\text { gastrectomy }\end{array}$ & 21 & 47.62 & 0.74 & $0.33-1.68$ & 0.473 \\
\hline $\begin{array}{l}\text { Distal } \\
\text { gastrectomy }\end{array}$ & 29 & 58.62 & & & \\
\hline \multicolumn{6}{|l|}{ Tumor location } \\
\hline Upper & 13 & 46.15 & Ref. & Ref. & 0.667 \\
\hline Middle & 9 & 44.44 & 1.06 & $0.34-3.35$ & 0.912 \\
\hline Lower & 28 & 60.71 & 0.71 & $0.27-1.82$ & 0.472 \\
\hline \multicolumn{6}{|l|}{$\begin{array}{l}\text { T stage (AJCC } \\
\text { 8th Edn) }\end{array}$} \\
\hline $\mathrm{TI} / \mathrm{T} 2$ & 12 & 91.67 & 10.22 & $1.37-75.98$ & 0.023 \\
\hline $\mathrm{T} 3 / \mathrm{T} 4 \mathrm{a}$ & 38 & 42.11 & & & \\
\hline \multirow{2}{*}{\multicolumn{6}{|c|}{$\begin{array}{l}\text { N stage (AJCC } \\
\text { 8th Edn) }\end{array}$}} \\
\hline & & & & & \\
\hline No & 14 & 78.57 & Ref. & $0.22-5.38$ & $<0.001$ \\
\hline $\mathrm{NI}$ & 13 & 78.57 & 1.09 & $0.74-11.88$ & $<0.001$ \\
\hline N2 & 11 & 45.45 & 2.97 & $2.64-35.39$ & 0.125 \\
\hline N3 & 12 & 8.33 & 9.66 & & 0.001 \\
\hline
\end{tabular}

(Continued) 
Table 2 (Continued).

\begin{tabular}{|c|c|c|c|c|c|}
\hline Category & $\mathbf{n}$ & $\begin{array}{l}\text { 3-y OS } \\
(\%)\end{array}$ & HR & $95 \% \mathrm{Cl}$ & $\mathbf{P}$ \\
\hline \multicolumn{6}{|l|}{ LVI } \\
\hline Yes & 15 & 33.33 & 0.40 & $0.17-0.91$ & 0.029 \\
\hline No & 35 & 62.86 & & & \\
\hline \multicolumn{6}{|l|}{ PNI } \\
\hline Yes & 5 & 20.00 & 0.38 & $0.13-1.12$ & 0.081 \\
\hline No & 45 & 57.78 & & & \\
\hline \multicolumn{6}{|l|}{$\mathrm{CgA}$} \\
\hline Positive & 39 & 53.85 & 0.92 & $0.27-3.21$ & 0.902 \\
\hline Negative & 11 & 54.55 & & & \\
\hline \multicolumn{6}{|l|}{ Syn } \\
\hline Positive & 40 & 50.00 & 0.48 & $0.19-1.22$ & 0.123 \\
\hline Negative & 10 & 70.00 & & & \\
\hline
\end{tabular}

Abbreviations: OS, overall survival; $\mathrm{HR}$, hazard ratio; $\mathrm{Cl}$, confidence interval; LVI, lymphovascular invasion; PNI, perineural invasion; CgA, chromogranin A; Syn, synaptophysin.

Furthermore, whether it is appropriate to use the prognostic TNM staging system for gastric adenocarcinoma in NEDGC patients is what we concerned about. The current study showed the trend of difference in survival among NEDGC patients at different $\mathrm{T}$ and $\mathrm{N}$ stage, and N3 was demonstrated as an independent risk factor for disease prognosis. As for no significant prognostic value of $\mathrm{T}$ stage and $\mathrm{N} 0 \sim \mathrm{N} 2$ stage in the multivariate analysis, one important reason may be the limited cases. On the other hand, we did not include stage $\mathrm{T} 4 \mathrm{~b}$ or $\mathrm{M} 1$ cases since inappropriate for $\mathrm{R} 0$ resection, so we are unable to examine the prognostic implication of $\mathrm{M}$ stage. Nonetheless, our results do suggest that advanced $\mathrm{T}$ and $\mathrm{N}$ stage correlates to poor disease prognosis, and further analysis in this regard should be encouraged to reach a more accurate evaluation of prognosis.

Preoperative high NLR status had a negative prognostic effect in the patients with NEDGC is another interesting finding in the current study. As we have known, NLR represents an inexpensive marker of host inflammation. In the prior literature, a high NLR has been demonstrated to be prognostic in the advanced disease setting for a variety of solid tumors, including gastric cancer. ${ }^{14-17}$ Overall, our finding of this study is in keeping with the published literature, with a wealth of recent data of NEDGC suggesting that inflammationbased prognostic indicators such as the NLR are also
Table 3 Univariable (Continuous Variables) Cox Regression Analyses of OS

\begin{tabular}{|l|l|l|l|l|l|}
\hline Category & Survival & Dead & HR & $95 \%$ CI & P \\
\hline Age & $60.48(8.31)$ & $62.83(12.40)$ & 1.02 & $0.98-1.07$ & 0.314 \\
BMI (kg/m $)^{2}$ & $22.80(2.62)$ & $22.63(2.93)$ & 0.95 & $0.82-1.11$ & 0.549 \\
Operation time & $210.00[117.0]$ & $184.00[80.0]$ & 1.00 & $0.99-1.00$ & 0.298 \\
(min) & & & & & \\
Blood losing & 300.00 & $300.00[275.0]$ & 1.00 & $1.00-1.00$ & 0.230 \\
volume (mL) & {$[225.0]$} & & & & \\
Tumor size (cm) & $4.26(2.28)$ & $5.50(2.20)$ & 1.18 & $1.01-1.39$ & 0.038 \\
Ki-67 positive & $0.53(0.23)$ & $0.47(0.22)$ & 0.29 & $0.05-1.78$ & 0.179 \\
index (\%) & & & & & \\
\hline Preoperative test & & & & & \\
WBC & $7.07(1.54)$ & $6.26(1.87)$ & 0.80 & $0.61-1.03$ & 0.088 \\
Neutrophils & $0.60(0.10)$ & $0.64(0.11)$ & 38.59 & $0.57-2626.41$ & 0.090 \\
Lymphocytes & $0.28(0.08)$ & $0.25(0.10)$ & 0.05 & $0.00-4.96$ & 0.198 \\
Monocytes & $0.07[0.02]$ & $0.07[0.03]$ & 1.09 & $0.92-1.3$ & 0.316 \\
NLR (Neu/Lym) & $2.00[1.33]$ & $2.51[2.58]$ & 1.19 & $1.03-1.39$ & 0.019 \\
LMR (Lym/ & $3.99[1.79]$ & $2.91[2.46]$ & 0.96 & $0.81-1.14$ & 0.663 \\
Mono) & & & & & \\
Platelet & $224.00[72.0]$ & $202.00[80.5]$ & 1.00 & $0.99-1.00$ & 0.791 \\
Hemoglobin & $127.26(20.92)$ & $113.87(22.49)$ & 0.98 & $0.96-0.99$ & 0.011 \\
Albumin & $38.89(3.77)$ & $37.48(3.98)$ & 0.92 & $0.83-1.01$ & 0.094 \\
Prealbumin & $212.93(53.84)$ & $173.87(61.26)$ & 0.99 & $0.98-1.00$ & 0.007 \\
Blood glucose & $5.20[0.95]$ & $5.40[1.1]$ & 0.76 & $0.52-1.12$ & 0.166 \\
\hline
\end{tabular}

Abbreviations: $\mathrm{HR}$, hazard ratio; $\mathrm{Cl}$, confidence interval; $\mathrm{BMI}$, body mass index.

generally associated with poor survival in NEDGC patients. Furthermore, since there is a lack of consensus regarding the most appropriate cut-off evaluation of the NLR, we treated it as a continuous variable. Univariate Cox regression test showed that the median value of the surviving group and the non-survivors was 2.51 and 2.00 , respectively. It may be helpful to get a consensus regarding the definitions of "high" versus "low" NLR value of NEDGC patients in future studies.

As shown in Figure 3, in the last decade, there was an increase not only in the incidence of NEDGC but also in the use of laparoscopic gastrectomy as the treatment. Since the first case of laparoscopic-assisted distal gastrectomy reported by Kitano et al in 1994, ${ }^{18}$ laparoscopic gastrectomy has been popularized with the expanding indication and decreasing complication in the past twenty years. Supported by a series of high-quality RCTs, ${ }^{19,20}$ laparoscopic gastrectomy for early gastric cancer is accepted widely. For locally advanced gastric cancer, laparoscopic gastrectomy with D2 dissection is still under debate, waiting for the long-term outcomes of relevant RCTs. ${ }^{21-23}$ According to our data, laparoscopic gastrectomy is an independent risk factor for 3-year OS in the same tumor staging baseline as in the open group. This phenomenon may due to 

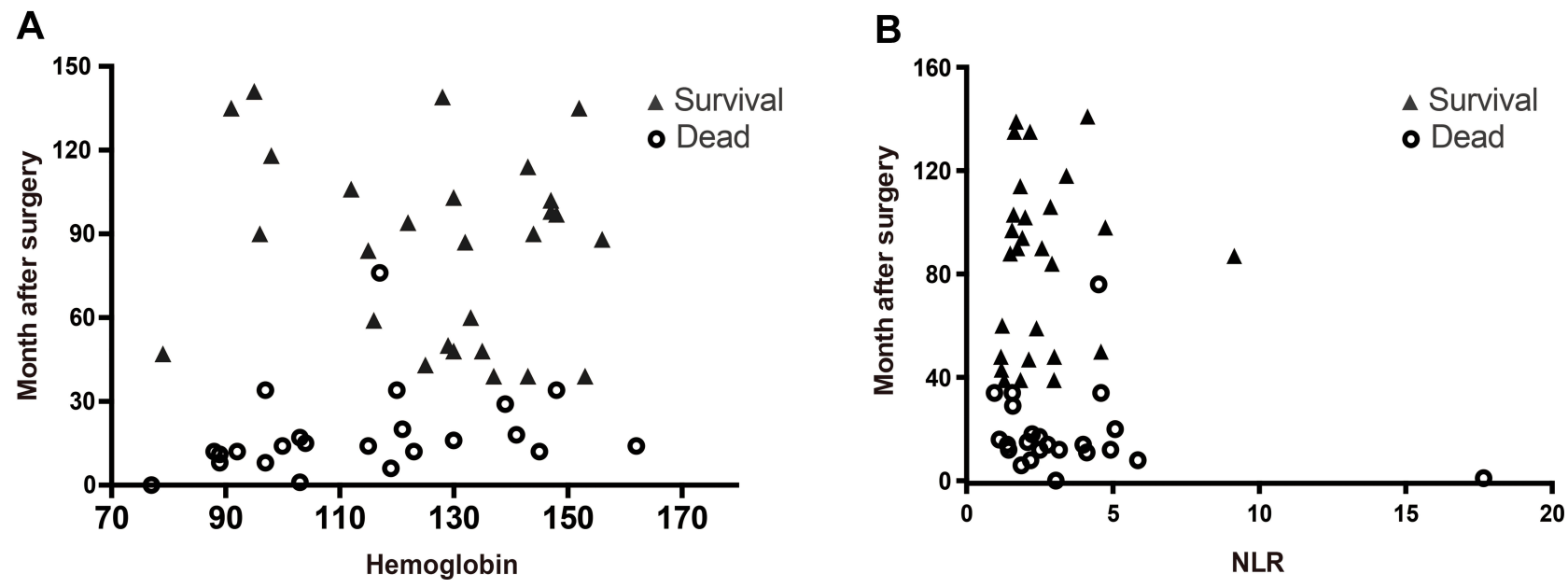

Figure 2 Survival analysis of NEDGC patients based on univariate Cox regression analysis. (A) Lower hemoglobin level was statistically associated with worse OS, since the median value of the surviving group and the non-survivors was 127.26 and II3.87g/L, respectively ( $\mathrm{HR} 0.98$; $95 \% \mathrm{Cl}$ : $0.96-0.99$; $\mathrm{P}=0.0 \mathrm{II}$ ). (B) Higher neutrophil-tolymphocyte ratio (NLR) was shown associated with worse OS, with the median value of the surviving group and the non-survivors was $2.5 \mathrm{I}$ and 2.00 , respectively (HR I.19; 95\% Cl: I.03-I.39; $P=0.019$ ).
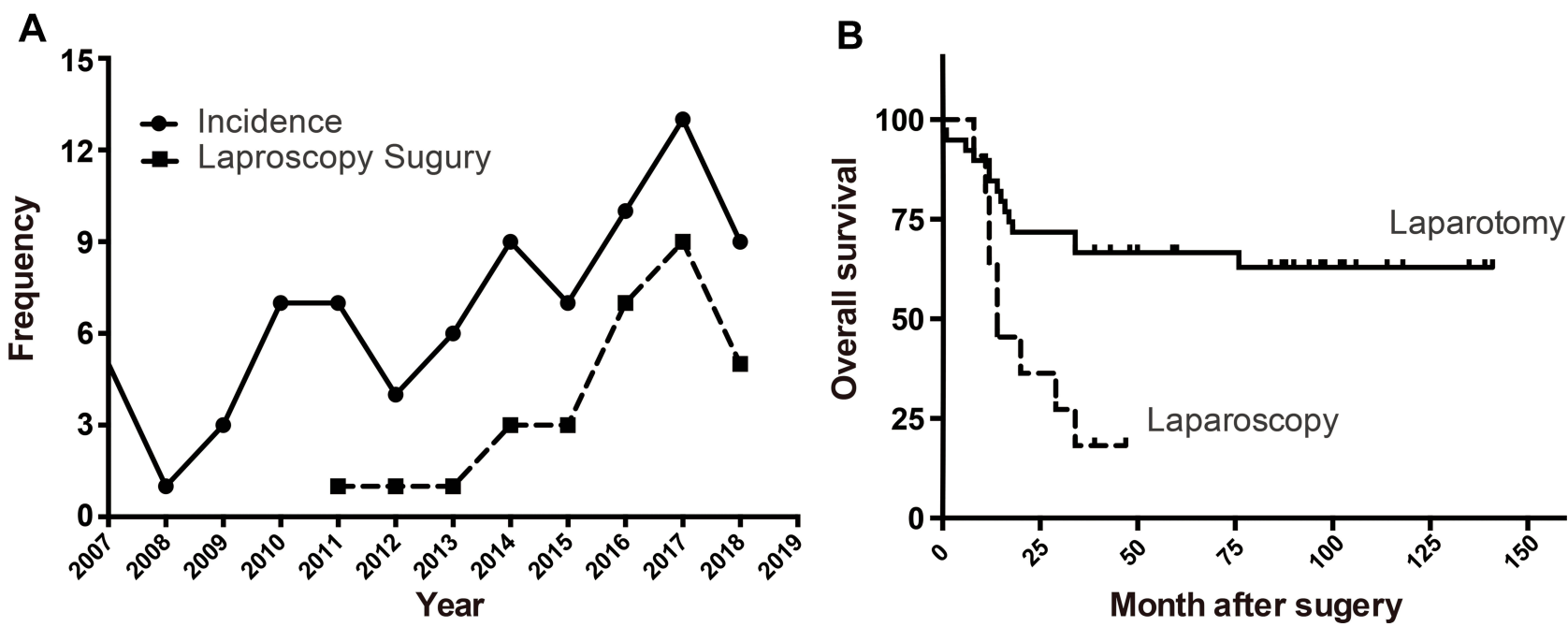

Figure 3 Incidence of NEDGC and cases of laparoscopic gastrectomy with Kaplan-Meier method estimated OS. (A) The number of newly diagnosed patients increased from 2007 to 2018 , and the increased instances of laparoscopic gastrectomy in the past 5 years. (B) Survival analysis found significantly worse survival laparoscopic than laparotomy gastrectomy $(P=0.004)$.

sample selection bias, that since laparoscopic gastrectomy is a new technique developed in recent years, the number of patients eligible for lap group is relatively small. Furthermore, regarding most of the NEDGC patients were advanced-stage cases, it is a caution for us to select proper indications to perform operative laparoscopy. How to make sure that the surgeons are qualified with skillful technique to accomplish the laparoscopic gastrectomy even with D2 dissection is also very important. Delightedly, bunds of organizations were conscious of this problem, and consensus on qualifying surgeons to perform laparoscopic gastrectomy was developed and promoted..$^{24,25}$ So, it is not the time to say "no" to perform laparoscopic gastrectomy on NEDGC patients. High-quality RCTs are necessary to explore this issue clearly in the near future. Still, proper indications selection and accumulation of laparoscopic gastrectomy skills are prerequisite, especially for the locally advanced NEDGC.

This study has several limitations. First, there is selection bias due to the nature of the single-center retrospective study. Second, due to the rare incidence, limited cases were qualified to analyze the prognosis, which may be affected by the disunity of chemotherapy postoperative either. Third, our study only included the resectable 
A

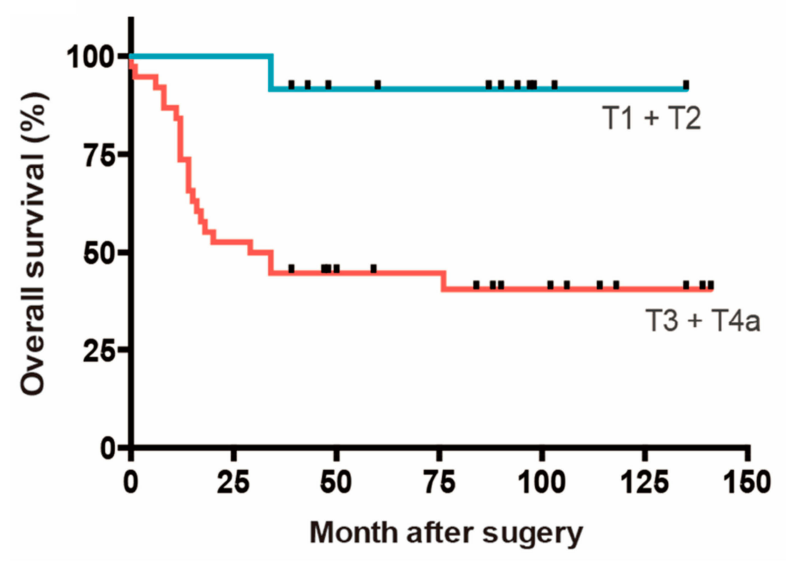

B

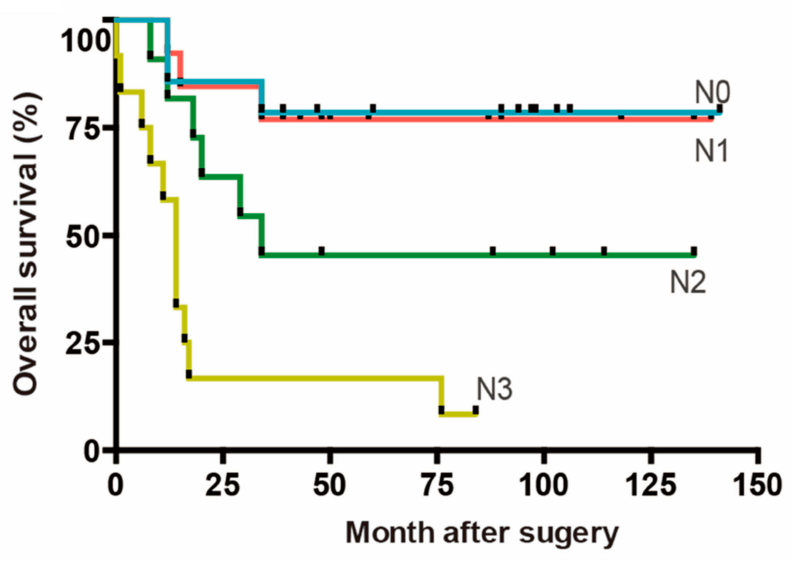

Figure 4 Kaplan-Meier method estimated OS in NEDGC patients grouped by (A) T stage of the primary tumor. Log rank analysis was carried out in stage TI+T2 and T3 $+\mathrm{T} 4 \mathrm{a}$ cases, and the difference in OS was determined $(P=0.023)$, (B) $\mathrm{N}$ stage of the primary tumor. Log rank analysis was carried out in different $\mathrm{N}$ stage cases. No significant difference was determined between stage $\mathrm{N} 0, \mathrm{NI}$, and $\mathrm{N} 2$ patients $(P=0.921$ and 0.125 , respectively), while a significant difference was determined between stage $\mathrm{N} 0$ and $\mathrm{N} 3$ patients $(P=0.001)$.

cases, which limited our ability to examine the prognostic implication of M stage in NEDGC patients. Last but not least, it is a data from Eastern countries, multicenter, prospective, large-sample analyses are needed for confirmation of our results.

In conclusion, the present study discovered that low preoperative hemoglobin level, laparoscopic-assisted gastrectomy, and advanced N stage (N3) were three independent risk factors for OS of NEDGC patients. These findings indicate that the tumor staging system for gastric adenocarcinoma also helps to predict the prognosis of NEDGC. Since most of the NEDGC patients were in the advanced stage, proper indications to perform operative laparoscopy should be selected, and a better screening project for gastric cancer (with or without NED) is needed. Due to rare incidence, there is still a poor understanding of NEDGC as a clinical

Table 4 Multivariable Cox Regression Analyses of OS

\begin{tabular}{|l|l|l|l|l|}
\hline Category & P & HR & \multicolumn{2}{|l|}{ 95\% CI } \\
\cline { 4 - 5 } & & & Lower & Upper \\
\hline Hb & 0.046 & 0.979 & 0.958 & 1.000 \\
\hline Operation types & 0.023 & 3.058 & 1.169 & 8.000 \\
(Laparotomy vs Laparoscopic) & & & & \\
\hline N stage (AJCC 8th Edn) & & & & \\
N0 & 0.001 & Ref. & & \\
NI & 0.442 & 1.960 & 0.352 & 10.924 \\
N2 & 0.050 & 4.250 & 0.998 & 18.099 \\
N3 & $<0.001$ & 11.977 & 3.025 & 47.420 \\
\hline
\end{tabular}

Abbreviations: $\mathrm{HR}$, hazard ratio; $\mathrm{Cl}$, confidence interval; $\mathrm{Hb}$, hemoglobin. entity. Further correct identification such as multicenter studies should be encouraged.

\section{Consent for Publication}

Patients provided written consent for the publication of their data.

\section{Acknowledgments}

We thank all the efforts made by the staff of Shanghai Huashan Hospital Department of Surgery and pathology.

\section{Author Contributions}

All authors made substantial contributions to conception and design, acquisition of data, or analysis and interpretation of data; took part in drafting the article or revising it critically for important intellectual content; gave final approval of the version to be published; and agree to be accountable for all aspects of the work.

\section{Funding}

The study is supported by the National Natural Science Foundation of China (NSFC) (81802901).

\section{Disclosure}

The authors declare that they have no competing interests.

\section{References}

1. The International Agency for Research on Cancer. WHO Classification of Tumours of the Digestive System. 4th ed. Lyon: IARC Press; 2010:1089. 
2. Lloyd RV, Osamura RY, Klöppel G, Rosai J. WHO Classification of Tumours of Endocrine Organs. 4th ed. Lyon: International Agency for Research on Cancer (IARC); 2017.

3. Farooq F, Zarrabi K, Sweeney K, et al. Multiregion comprehensive genomic profiling of a gastric mixed neuroendocrine-nonneuroendocrine neoplasm with trilineage differentiation. $J$ Gastric Cancer. 2018;18 (2):200-207. doi:10.5230/jgc.2018.18.e16

4. Chen ML, Yang M, Chen JY, et al. Clinicopathological characteristics and prognosis of gastric cancer with neuroendocrine differentiation. Chin Clin Oncol. 2018;23(7):615-620. doi:CNKI:SUN:LCZL.0.2018-07-008

5. Zhang TT, Sun D, Mao ZY, et al. Prognostic role of neuroendocrine cell differentiation in human gastric carcinoma. Int J Clin Exp Med. 2015;8(5):7837-7842.

6. Bozkaya Y, Ozdemir N, Colak A, et al. Gastric adenocarcinoma with neuroendocrine differentiation: clinicopathological features and efficacy of modified DCF chemotherapy. J BUON. 2017;22(4):919-925 doi:10.1002/bjs. 10694

7. Park JY, Ryu MH, Park YS, et al. Prognostic significance of neuroendocrine components in gastric carcinomas. Eur $J$ Cancer 2014;50(16):2802-2809. doi:10.1016/j.ejca.2014.08.004

8. Chinese Pathologic Consensus Group for Gastointestinal and Pancreatic Neuroendocrine Neoplasm. Chinese expert consensus on gastrointestinal and pancreatic neuroendocrine oncology (2016 version). Chin Clin Oncol. 2016;21(10):927-946. doi:1009-0460(2016) 10-0927-20

9. Amin MB, Edge S, Greene F. American Joint Committee on Cancer (AJCC) Cancer Staging Manual. 8th ed. New York: Springer; 2016.

10. Chen WQ, Zhen RS, Baade PD, et al. Cancer statistics in China, 2015. CA Cancer J Clin. 2016;66(2):115-132. doi:10.3322/caac.21338

11. Song W, Yu QK. Analysis of clinicopathological features and prognosis of gastric carcinoma with neuroendocrine differentiation and mixed gonadal neuroendocrine carcinoma of the stomach. Tianjin Med J. 2014;42 (8):799-801. doi:10.3969/j.issn.0253-9896.2014.08.018

12. Chan DL, Clarke SJ, Diakos CI, et al. Prognostic and predictive biomarkers in neuroendocrine tumours. Crit Rev Oncol Hematol. 2017;113:268-282. doi:10.1016/j.critrevonc.2017.03.017

13. Mafficini A, Scarpa A. Genetics and epigenetics of gastroenteropancreatic neuroendocrine neoplasms. Endocr Rev. 2019;40(2):506-536. doi:10.1210/er.2018-00160

14. Grenader T, Waddell T, Peckitt $\mathrm{C}$, et al. Prognostic value of neutrophil-to-lymphocyte ratio in advanced oesophago-gastric cancer: exploratory analysis of the REAL-2 trial. Ann Oncol. 2016;27 (4):687-692. doi:10.1093/annonc/mdw012

15. Wang SC, Chou JF, Strong VE, et al. Pretreatment neutrophil to lymphocyte ratio independently predicts disease-specific survival in resec table gastroesophageal junction and gastric adenocarcinoma. Ann Surg. 2016;263(2):292-297. doi:10.1097/SLA.0000000000001189
16. Karki R, Man SM, Kanneganti TD. Inflammasomes and cancer. Cancer Immunol Res. 2017;5(2):94-99. doi:10.1158/2326-6066. CIR-16-0269

17. Ock CY, Nam AR, Lee J, et al. Prognostic implication of antitumor immunity measured by the neutrophil-lymphocyte ratio and serum cy tokines and angiogenic factors in gastric cancer. Gastric Cancer. 2017;20(2):254-262. doi:10.1007/s10120-016-0613-5

18. Kitano S, Iso Y, Moriyama M, et al. Laparoscopy-assisted Billroth I gastrectomy. Surg Laparosc Endosc. 1994;4(2):146-148. doi:10.1007/BF00590967

19. Kim HH, Han SU, Kim MC, et al. Effect of laparoscopic distal gastrectomy vs open distal gastrectomy on long-term survival among pati ents with stage I gastric cancer: the KLASS-01 randomized clinical trial. JAMA Oncol. 2019;5(4):506-513. doi:10.1001/ jamaoncol.2018.6727

20. Nakamura K, Katal H, Mizusawa J, et al. A Phase III study of laparoscopy-assisted versus open distal gastrectomy with nodal dissection for cl inical stage IA/IB gastric cancer (JCOG0912). Jpn $J$ Clin Oncol. 2013;43(3):324-327. doi:10.1093/jjco/hys220

21. Inaki N, Eton T, Ohyama T, et al. A multi-institutional, prospective, Phase II feasibility study of laparoscopy-assisted distal gastrec tomy with D2 lymph node dissection for locally advanced gastric cancer (JLSSG0901). World J Surg. 2015;39(11):2734-2741. doi:10.1007/ s00268-015-3160-z

22. Lee HJ, Hyung WJ, Yang HK, et al. Short-term outcomes of a multicenter randomized controlled trial comparing laparoscopic distal gastre ctomy with D2 lymphadenectomy to open distal gastrectomy for locally advanced gastric cancer (KLASS-02-RCT). Ann Surg. 2019;270(6):983-991. doi:10.1097/SLA.0000000000003217

23. Yu J, Huang H, Sun Y, et al. Effect of laparoscopic vs open distal gastrectomy on 3-year disease-free survival in patients with locally advanced gastric cancer: the CLASS-01 randomized clinical trial. JAMA. 2019;321(20):1983-1992. doi:10.1001/jama.2019.5359

24. Chinese Society of Laparoscopic Surgery, Chinese Endoscopist Association, Chinese Medical Doctor Association, et al. Expert consensus on quality control of the laparoscopic radical resection for gastric cancer in China (2017 edition). Chin J Dig Surg. 2017;16 (6):539-547. doi:10.3760/cma.j.issn.1673 $\square 9752.2017 .06 .001$

25. Kim HI, Hur H, Kim YN, et al. Standardization of D2 lymphadenectomy and surgical quality control (KLASS-02-QC): a prospective, observational, multicenter study [NCT01283893]. BMC Cancer. 2014;14:209. doi:10.1186/1471-2407-14-209
Cancer Management and Research

\section{Publish your work in this journal}

Cancer Management and Research is an international, peer-reviewed open access journal focusing on cancer research and the optimal use of preventative and integrated treatment interventions to achieve improved outcomes, enhanced survival and quality of life for the cancer patient.
The manuscript management system is completely online and includes a very quick and fair peer-review system, which is all easy to use. Visit http://www.dovepress.com/testimonials.php to read real quotes from published authors. 